\title{
Enabling Social Sustainability of E-Participation through Mobile Technology
}

\author{
Nixon Muganda Ochara* and Tendani Mawela \\ Department of Informatics, University of Pretoria, Pretoria, South Africa \\ ${ }^{*}$ Corresponding author. Email: nixon.ochara@up.ac.za
}

\begin{abstract}
The social sustainability of information and communication technology for development (ICT4D) projects such as e-government in developing nations remains a vexing issue. Particularly pertinent to the concept of e-government is that of electronic participation (e-participation) of citizens in services offered over an e-government platform, yet studies claim that such initiatives exacerbate the social exclusion problem. Globally, and specifically in Africa, the ineffective participation of citizens is marked by waning confidence in service delivery capabilities of political institutions, yet e-government is considered as one of the reform instrument for the attainment of good governance. Governments and pressure groups in many countries are realizing that these trends are problematic and are seeking to broaden and deepen citizen participation in governance, notably through the use of mobile technologies that continues to play a vital role in the trajectory of ICT development in Africa. This study advances the prominent role that mobile technology will play in anchoring e-participation strategies and policies to improve the social sustainability of ICT4D projects geared toward improving governance. The paper presents the results of cluster analysis of a survey aimed at assessing the accessibility, attitudes and the skills necessary for embedding mobile technology as part of an e-participation strategy.
\end{abstract}

Keywords: ICT for development; e-government; e-participation; ICT adoption; socio-economic development; South Africa

\section{Introduction}

Research on the proliferation of information and communication technologies (ICT's) in the developing world is growing. Our interest in this study is in how increased access to and engagement with ICT's may hold the potential to change the lives of citizens for the better. Our study focuses on those factors that influence the use of ICT's by citizens to access government services electronically (e-government) and how electronic participation (e-participation) manifests in this context.

Social sustainability, as part of the broader concept of sustainability as it relates to information and communications technology for development (ICT4D), requires citizen participation in governance, taking into account local traditions, differences within communities, empowering marginalized groups, sharing and aligning goals with local people and adapting to evolving community needs (Avgerou, 2010; Avgerous, 2008; Hayes \& Westrup, 2012). Of concern in Africa is whether e-government is sustainable on the current dominant Internet infrastructure which relies on an old model of computing or whether the mobile technology infrastructure, given high adoption rates in the continent, provides a better alternative for conceptualizing e-government. Noting that a majority of the socially excluded in Africa have some form of 
Internet access through mobile technology, the social sustainability of the e-government artifact calls for assessing alternatives that can help redress unintended consequences (digital exclusion) related to e-government and its longevity in the long run (Bailur, 2007). The study links the notion of social sustainability of e-government to e-participation, considered as an indicator of the effectiveness of e-government paradigm in realizing good governance objectives (see Ochara, 2012). Thus the principal research question that this paper seeks to address is: How can e-participation be enhanced using mobile technology for socially excluded citizens in a developing world context?

As the paper proceeds, key definitions of the concepts directly related to the title are presented. The e-government artifact is regarded as the public sector application of ICT for the transformation of governance in African countries. Governance is understood from the perspective that many developing countries have embraced, willingly or otherwise, the importance of effective governance as a precondition for effective development and poverty alleviation, with e-government as one of the tools for attaining good governance (Grindle, 2007, 2011). E-participation refers to as ICT-supported processes to ensure effective participation of various stakeholders in the governance process and in e-government service provision. Social sustainability moves us beyond the conceptualization of sustainability that is limited to economic factors to embrace social factors that recognize the need to individual and community acceptance of a particular technological artifact (Bailey, 2009). Since the paper is concerned with exploring the use of mobile phones for enabling e-participation, the focus of the paper is on the social factors enumerated under the theoretical framework.

The research paper is structured as follows: first, it provides a literature review and background focusing on the concepts of ICT's being utilized toward the achievement of the socio-economic development of countries (ICT4D); electronic government (e-government) and e-participation as a driver of ICT4D initiatives. Second, the paper outlines the approach followed to investigate the research problem. This is followed by a discussion on the main findings of the study and finally conclusions and opportunities for future research are offered.

\section{Informing literature}

\subsection{Digital divide, e-government and sustainable development}

Adoption of e-government in a country is linked to good governance which is claimed to have an impact on economic development of a country (Goldsmith, 2007); thus, increasing levels of e-participation of the socially excluded groups is likely to positively impact on the welfare of such groups. It is generally accepted that the development of a country can be mainly achieved through the improvement of the socio-economic circumstances and quality of life of the marginalized and poor citizens (Bhuiyan, 2011). An analysis of the development discourse reveals the persistent belief that ICT's are enablers of development to the extent that they are viewed as resources that can be used to change people's lives (Andrade \& Joia, 2011). This belief has gained broader acceptance and in the public sector manifests through e-government initiatives.

Developing countries based in Africa continue to make significant investments aimed at building new ICT infrastructures, expanding mobile network coverage and improving broadband infrastructure. These ICT investments are aimed at spurring activities that can lead to the realization of social and economic objectives of various broader policy agendas, notably Poverty Reduction Strategy Programs that have been developed as part of Millennium Development Goals (African Union, 2010). The efforts in improving and expanding ICT infrastructure has resulted in increased ICT usage, evidenced by the increase in number of Internet and mobile phone users in many sub-Saharan countries of Africa. For instance, the numbers of Internet users have increased from 4.5 million in 2000 to 168 million users by the end of 2012 (IWS, 2013); 
while the number of households with Internet access has increased from nearly zero in 2005 to seven million in 2013 (ITU, 2013). Despite the positive trends in ICT infrastructure development and usage, a digital divide persists, not only within the various demographic groups within the developing countries, but also between the developed and developing economies as well. For instance, access to ICT infrastructure is still considered to be costly, while relatively low ICT skills levels and unfavorable economic environments hinder the leveraging of the potential of ICT infrastructure for socio-economic development (Bilbao-Osorio, Dutta, \& Lanvin, 2013).

Following Belanger and Carter (2009), we consider the digital divide as a distinction between individuals and/or economies/groups that are computer literate and computer illiterate; specifically related to the major divide between access and skills. Research on the socioeconomic impact of the digital divide is not new (Hüsing \& Selhofer, 2002) with a number of studies focusing on the speed of ICT adoption; abilities to use ICTs and its attendant benefits; and attitudes related to adoption and usage (Donat, Brandtweiner, \& Kerschbaum, 2009). However, the digital divide persists and in developing countries where the impact is greater, the concern is that these countries are not only falling behind, but also falling apart (Collier, 2008). Thus in various discourses on the digital divide, discussions on the opportunities and threats in the current information - intensive society abound and due to the growing use of ICTs in both public life and private life, the possession of ability, skills and attitudes of those who are currently disadvantaged have become important prerequisites for realizing social inclusion. Taking cognizance of the growing research on ICT in developing countries, we seek to contribute to research on the digital divide, since there are still persistent legitimate concerns that despite beneficial impacts of ICTs in general - paradoxically - information use is still disproportionate and in favor of certain segments of society resulting in the social exclusion of large segments of society (Almuwil, Weerakkody, \& El-Haddadeh, 2011). Thus political, social and economic discourses on ICTs in developing countries are inundated with a flurry of concepts such as e-participation, social sustainability, e-inclusion, etc. - whose origins can partly be linked to the concept of "digital divide" (Almuwil et al., 2011).

The legitimacy of the digital divide issue is even more poignant when the potential impacts of ICTs are related to governance mechanisms such as e-government. For instance, in the findings of the United Nations (UN) E-Government Survey of 2012, governments worldwide continue to widen the transformative role of e-government by investing in ICT initiatives aimed at enhancing public sector efficiencies and streamline governance systems to support sustainable development (UN, 2012). The transformative aspect of e-government critically brings to the fore the quest for more citizen participation in governance, yet this very emphasis on e-participation by these latter e-government initiatives is a stark reminder of the legitimacy of the digital divide concern that continue to shroud ICT applications to date. Various researchers specifically claim that e-government initiatives are aimed at realizing a number of socially desirable outcomes including but not limited to improving quality of life, providing better access to education, encouraging and facilitating active participation of citizens in government, bridging the digital divide, eradicating distance and reducing the communication and information costs (Hanna, 2008; Jaeger \& Thompson, 2003; Norris, 2001). The implication is that a key benefit or value flow of implementing e-government is on reducing the digital divide and facilitating citizen participation in governance. This meaning provides a conceptual link between the idea of public value and e-government and e-participation and digital divide.

The concept of public value is part of a wider debate on post-New Public Management government reform that seeks to broaden understanding of the benefits of e-government applications (Benington \& Moore, 2011) and partly emphasizes introducing innovations in the delivery of government services in order to enrich governments' interaction with citizens (Meynhardt, 2009). The importance of adopting innovative approaches to realize e-participation is 
obvious, especially in developing countries faced with resource scarcity challenges and where egovernment implementation is also linked to attaining sustainable development (UN, 2012; Yildiz \& Saylam, 2013). In this context, it is imperative that for e-participation to contribute to sustainable development, more effort should be geared toward promoting user uptake among the vulnerable and socially excluded citizens.

By addressing the research question, we seek to elevate the role of mobile technology as inevitable in realizing and sustaining e-participation amongst the socially excluded groups in Africa. This will enable us to make a contribution in mobile government (m-government) research considered as an "extension of e-government to mobile platforms," as well as the "strategic use of government services and applications" which are only possible through mobile technologies (mobile telephone, Personal Digital Assistants and wireless Internet infrastructure) (Misuraca, 2009). Following (Klecun, 2008), we argue that e-participation depends on access, skills and attitude toward mobile technology use for e-government services. Given that e-government initiatives are linked to sustainable development, any form of digital exclusion related to such initiatives necessarily compounds social exclusion, limiting people's opportunities for personal, social and economic development. We believe this is the case and improvements in e-participation that will positively impact on the sustainability of e-government initiatives in developing countries of Africa. Thus, the study focused on socially excluded groups as the context for this study.

The above analyses point to an increasing perception that e-government can act as a means (or a tool or instrument) to achieve good governance and therefore occupies a vantage point in helping to realize sustainable development. Given the role that e-government likely to have on sustainable development, the current generation needs to consider how it is conceptualized, especially in developing countries of Africa where social exclusion problems related to technology development persist, yet the adoption of mobile technology holds potential in transformation of lives. So naturally, with the recognition of the promise of the potential of mobile technology in transforming e-services in Africa, the issue of sustainability and specifically social sustainability is critical in e-government adoption.

The concern with e-participation from various studies relates to the fact that e-government has generally had an ineffective citizen-centric focus; thus scholars and practitioners alike battle with alternative conceptualizations of e-government based on a mobile computing platform (m-government). We will seek insight into how mobile technology can enhance the citizencentric focus of e-government through recourse to the metaphor of Bricolage, which provides a way of re-thinking the issue of user participation in terms of unintended consequences of a technology (Ciborra, 1998; Markus, 2000). "Bricolage”, which Ciborra defines as “...tinkering through the combination of resources at hand", implies that the mobile device, which has found various uses in Africa and is readily available, can be leveraged for realizing e-participation.

One of the challenges related to sustainability of ICT4D projects is how to measure the social impact of e-governments projects (Ali \& Bailur, 2007); thus the continuing paradox of how to realize e-participation. However, mass scale adoption of mobile technologies in Africa demonstrated in the uptake of e-services such as M-Pesa in Kenya, South Africa and Nigeria provides an opportunity for considering how to achieve the same "feat" as it related to e-government services. While recognizing that attaining mass scale adoption of e-government services is partly hampered by inadequate national technological infrastructure which leads to the social exclusion of large segments of the population (Ochara, 2012); the success of e-services adoption in the commercial sector in Africa has some lessons. In this paper, we see the problem of social exclusion as providing traction for the use of network Bricolage as a possible metaphor that can aid in explaining how to achieve mass scale adoption of e-government services. The concept of network Bricolage (Oliver \& McKague, 2009) is adapted in this case to mean the combination 
of existing actors (individual mobile phone users) and resources (mobile devices and other social resources) into a formal network to generate self-sustaining and individualized incentivization for the realization of the social impact of e-government (aka e-participation). Given that network Bricolage is considered as an effective in low-income economic settings or other resource-constrained environments because of its focus is on engagement with local resources and expertise to achieve economic goals (Baker \& Nelson, 2005; Garud \& Karnøe, 2003); we will use the concept to enrich our discussions in later sections.

\subsection{E-participation in developing countries}

Heeks (2008) proposes an emerging phase in the ICT4D discourse which focuses on acknowledging that in the midst of the explosion of the mobile phone, our historical preoccupation with the personal computer (PC) for expanding Internet access will not suffice. The next phase, ICT4D 2.0, looks to mobile technologies to address the "technical question of how to deliver the Internet to the remaining five billion people who lack such access" (Heeks, 2008).

This paper puts forward e-participation principles as an alternative for broadening access to the Internet and consequently access to e-government services. E-participation involves communication, feedback and involvement in decision-making which is supported by citizens having access to technology and a culture and leadership that is open to involving citizens in the political, governance and service delivery processes (UN, 2012). Furthermore, it is suggested that e-participation is a critical element in the betterment of people's socio-economic circumstances where government becomes a facilitator of information and services and not a controller thereof (UN, 2012). E-participation programs may be pursued for a multitude of reasons: service delivery, distributing information to citizens, garnering support among citizens, sourcing citizens' feedback for decision-making processes, supporting political processes and assessing what citizens require from their governments.

A review of the literature raises fundamental challenges for e-government and subsequently eparticipation in the developing world. These include insufficient funding to spend on ICT (Heeks, 2002; Ho, 2002); partnership and collaboration across public, private and non-profit sectors is lacking (Ndou, 2004); and lack of e-readiness necessary for implementing e-government initiatives. E-readiness incorporates the necessary technical infrastructure, data systems, policy issues and legal environment, human capital and skills, as well as a supporting strategy and leadership commitment (Heeks, 2002; Ndou, 2004). Other reasons for failure are that often e-government initiatives are driven by external and mostly western agendas (Heeks, 2002); there is a complex and turbulent global political environment coupled with change management issues (Chou, Chen, \& Pu, 2008; Ndou, 2004); and the increasing threat of the digital divide between the "haves" and "have-not's" (Basu, 2004). Lastly, the resistance from public sector employees (Chou et al., 2008) and a lack of integrated project planning and effective management and relevantly skilled project managers are also cited (Andrade \& Joia, 2011; Reffat, 2003).

\subsection{South African context}

South Africa, a developing nation that may be viewed as a country of contrasts, has an estimated population of approximately 51 million (STATSSA, 2012). It is an upper middle-income country that however still battles with disparities, unemployment and poverty (Abrahams \& Newton-Reid, 2008). Through the recent national Census, the government reports that $40.5 \%$ of the population has completed secondary education (high school) or tertiary qualifications. Furthermore, $8 \%$ of households do not have access to tap (piped) water, 5\% do not have access to toilet facilities with $15 \%$ lacking access to electricity (STATSSA, 2012). On the 
ICT perspective, the government indicates that most households have access to a mobile phone $(88 \%)$ whilst over half the households in the country do not have access to the Internet $(64.8 \%)$, whereas $16 \%$ of households access the Internet via a mobile phone. Against this scenario, South Africa is one of the developing nations that has made a commitment to the use of ICT's toward the goals of socio-economic progress. The country has embarked on the task of reviewing and updating of the National ICT Policy (Department of Communications, 2012). Also, South Africa has undertaken a myriad of e-government projects at the three levels of government (Local, Provincial and National) in a quest of addressing the digital divide. Yet, the country faces challenges in deregulating the telecommunications industry and ensuring that the Internet becomes accessible and affordable to the majority of poor citizens (Mukabeta, Owei, \& Alexander, 2008). Further to this, the country sees that low levels of literacy and citizens are lacking in "e-skills." There is also a burden of balancing the costs of pursuing e-government with the daily demands for scarce resources in young democracy (Mukabeta et al., 2008). In addition, the success rates of e-government have been inconsistent and disappointing (Heeks, 2002) and this reality elevates the need to ensure that the value of e-government projects is clearly understood and realized for citizen's beneficiation. We argue that e-government requires a reorientation toward the citizen. As Silva and Westrup (2009) highlight "potential is being identified for ICT4D to become more accessible and more user centered." The UN (2012) indicates that ICT's may be used to pursue development through focusing on including citizens in the process through what is viewed as e-participation.

\subsection{Conceptual model development}

A variety of research has been undertaken on the issues of access, skills and attitude as they pertain to ICT implementations. These areas are further discussed in light of the conceptual model supporting this research study.

\subsubsection{Access}

The World Economic Forum highlights that despite the fact that ICTs are becoming increasingly widespread, the problem of access and usage remains important. Various scholars have attempted to address the issue of user Access to ICT's. For instance, Sipior and Ward (2012) conducted research on the digital divide within a public housing community. Their study showed the significance of a community organizing plan aimed at gaining Internet access supported by training to advance e-government participation among the techno-disadvantaged (Sipior \& Ward, 2012). Hilbert (2010) conducted research into the access aspect of the digital divide. Essentially the study sought to understand the financial feasibility of offering universal ICT services in the Latin American context. The paper concludes by highlighting that the "long-standing structural characteristics of the developing world could be about to deepen the vicious circle between inequality and technology diffusion; the numbers have shown that the challenge of breaking this circle is a formidable one" (Hilbert, 2010, p. 768). Thus on the one hand, researches on practical solutions for addressing the matter of access are becoming increasingly necessary (Hilbert, 2010). Yates, Gulati, and Tawileh (2010) and on the other hand, it indicates that there is a dearth of research that offers explanations for the digital divide and the effects of policies that aim to increase citizen access to ICT.

This study seeks to contribute to the dialogue regarding how better access to various ICT's may further contribute to addressing the persistent digital divide in the context of growing mobile phone adoption in the developing world. 


\subsubsection{Skills}

One of the key issues central to the conceptualization of the persistence of the digital divide is the shortage of ICT skills (Van Deursen \& Van Dijk, 2010). Van Dijk and Hacker (2003) had previously warned that "the fundamental task of future society will be to prevent structural inequalities in the skill and usage of ICTs from becoming more intense" (p. 324). Skills are important in enabling citizens to utilize ICT's and thus participate in a variety of social arenas. The World Economic Forum indicates that skills are critical for knowledge-based, information-rich societies and these are crucial for employment and development (Bilbao-Osorio et al., 2013). A study on Internet skills offers a framework for categorizing skill as: Operational Skills: "The skills to operate computer and network hardware and software"; Information Skills: "The skills to search, select and process information in computer and network sources"; and Strategic Skills: "The capacities to use these sources as the means for specific goals and for the general goal of improving one's position in society" (Van Deursen \& Van Dijk, 2010). These various skills may be viewed as an essential driver of the usage of ICT's (Bilbao-Osorio et al., 2013) and a weak skills base can hinder a country's capacity to exploit ICT4D purposes.

Gomez, Abokhodair, Bayo, and Park (2013) researched the barriers to ICT use within marginalized communities. The study found that addressing the lack of technical skills coupled with emotional barriers was critical to ensuring that the communities are enabled to use technologies so as to fulfill their information and development needs (Gomez et al., 2013). Khan, Moon, Rhee, and Rho (2010) indicate that a main challenge of e-government within the developing world context is the low ICT literacy and skills of e-government users (Khan et al., 2010). The Khan et al. (2010) study showed that skills required for the sustainability of e-government are not merely technical; however, they included a broader set of skills to enhance e-skills (Khan et al., 2010). Alternatively, Wolcott, Kamal, and Qureshi (2008) found that IT user skill was a major limitation toward the adoption and use of ICT by micro-enterprises (Wolcott et al., 2008). Similarly, Mutula and Van Brakel (2007) found that Botswana, considered as a developing country, had an acute shortage of high-skilled ICT personnel to take advantage of the emerging digital economy in the country. The study also indicates that further research is required to provide a holistic understanding of the ICT skills needs of this developing nation (Mutula \& Van Brakel, 2007).

This study seeks to contribute to the dialogue regarding how improving user ICT Skills may further contribute to addressing the persistent digital divide in the context of growing mobile phone adoption in the developing world.

\subsubsection{Attitude}

Research on user attitude toward various ICT's is growing; however, as Wunderlich, Wangenheim, and Bitner (2013) highlight there is a limited research in this area thus necessitating further research (Wunderlich et al., 2013). A diverse set of studies have been conducted on the area of attitude of users toward ICT's. For instance, Edmunds, Thorpe, and Conole (2012) looked at the attitudes of students toward using ICT's in their studies, work and social environment. The study, using the Technology Acceptance Model, found that attitudes to the technology are influenced by the usefulness and ease of use of the technology. It also highlighted that ICT is perceived most positively in the work environment and technology use at work is a significant driver for technology use in other environments (Edmunds et al., 2012). Furthermore, Heikkinen, Nurminen, Smura, and Hammainen (2012) conducted research with the objective of understanding the behavior of mobile phones users toward energy consumption. They utilized questionnaires and usage monitoring to study the behavior and attitudes of the users. Another study aimed to understand the attitudes of users toward e-book reader technology (Lai \& Chang, 2011). The research puts forward a causal model that explores 


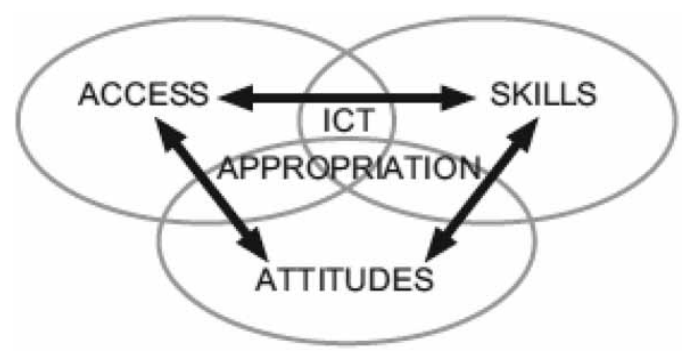

Figure 1. Access, skills and attitudes framework. Source: Verdegem and Verhoest (2009).

how convenience, compatibility and media richness affect users' attitudes toward the e-book readers for reading (Lai \& Chang, 2011). Furthermore, Zhang and Sun (2009) argue that "Despite the theoretical importance of attitude, it has not achieved consistent attention in IS research on ICT acceptance and continued use" (Zhang \& Sun, 2009). Thus, the issue of user attitude toward the use and acceptance technology is an ongoing area of relevance for ICT studies.

This study seeks to contribute to the dialogue regarding how enhanced understanding of user attitudes towards ICT's may further contribute to addressing the persistent digital divide in the context of growing mobile phone adoption in the developing world.

\subsubsection{The ASA model}

This quantitative research paper utilizes an a priori model and aims to test this model using new data. This research paper draws on the theoretical model of ICT acceptance and use as proposed by Verdegem and Verhoest (2009). Their model argues that providing citizen with access to ICT products does not necessarily guarantee that the citizens will use the ICT products. Verdegem and Verhoest (2009) found that to understand the acceptance or use of ICT's, the access to ICT's, ICT skills and attitudes toward ICT of the citizens being targeted must be considered in relation to the perceived utility of the ICT product.

We elaborate on the "Access, Skills and Attitude" approach from the Verdegem and Verhoest's (2009) conceptual model (see Figure 1) and propose that the preconditions for citizen e-participation and uptake of e-government products and services are fourfolds: citizens need to have the necessary technical skills to use the products, citizens also need to have access to the ICT's products, citizens must believe that there is value in using the ICT products and finally citizens must want to use the products and services. Thus, e-participation is said to be a function of access, skills, attitude and the perceived utility of the e-government products.

The Verdegem and Verhoest's (2009) theoretical model, having informed the propositions, is also used to support the choice of constructs and variables included in the questionnaire. The research study aimed at testing the following constructs (Figure 2).

The constructs outlined in Figure 2 were used to identify factors influencing e-participation. Within Africa, it is found that mobile phone penetration is high (Heeks, 2010) as compared to the PC or laptops.

\section{Research methodology}

This research study followed the survey method since it is fundamentally rooted in the positivist paradigm and utilized a questionnaire to collect data aimed at addressing the research area. 


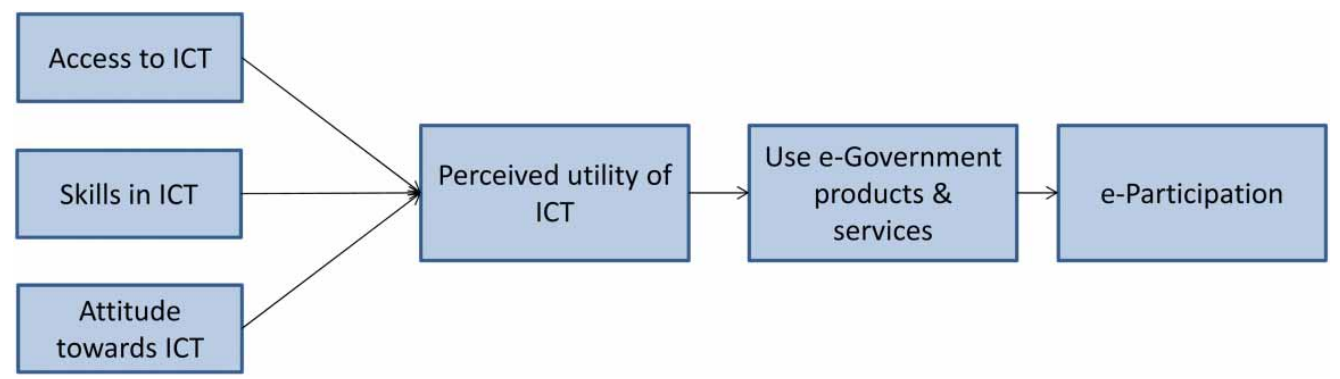

Figure 2. Primary constructs.

Surveys have been criticized for various limitations such as lacking depth, providing a snapshot of a single point in time and may overlook details that cannot be captured through counting and statistical analysis (Oates, 2006). However, the research benefited from using the survey method since it allowed for a more widespread and inclusive coverage of the target population.

\subsection{Instrument development}

The model of Verdegem and Verhoest (2009) was used deductively to build a research instrument consisting of a self-administered questionnaire which was structured in two parts. The first section aimed to capture the demographic profile of respondents (including gender, age, qualification level and job level). The second section aimed to assess the utility of e-government for e-participation through providing 37 statements to respondents that were aligned to the issues of access, skills, attitude and utility of ICT's. A five-point Likert scale was used to assess respondent's feelings toward the statements (strongly disagree, disagree, indifferent, agree and strongly agree). The matters of validity and reliability were assessed by the research team. The researchers subsequently reviewed the statements through several iterations to ensure that they were drafted in a simple and easy to understand English and reflected the concepts being tested correctly.

\subsection{Research procedures, population and sample}

The target population was South African citizens in general with a particular focus on those that are socially and digitally excluded. Two members of the research team are based in the economic hub of South Africa, in the Gauteng Province and this area was the main source of data collection for the research study. Non-probabilistic sampling methods were applied, namely a combination of convenience and judgment sampling. Data were collected at various sites in the province (Table 1).

In total, 220 questionnaires were administered, with 120 completed correctly and free from errors resulting in a response rate of 55\%. The questionnaire resulted in quantitative data that were captured and analyzed statistically using the IBM's SPSS tool. Cluster analysis was used to group variables by assigning polarities to the clusters using item means.

\section{Analysis of results}

\subsection{Descriptive analysis}

There were three variables (gender, age and education) that were used to capture the demographic profile of the 120 valid responses that were received. Fifty-five percent were female, 
Table 1. Cluster sampling.

\begin{tabular}{lcc}
\hline Site name & $\begin{array}{c}\text { Respondents } \\
(N)\end{array}$ & Description \\
\hline $\begin{array}{l}\text { CIDA College - Johannesburg } \\
\text { Campus }\end{array}$ & 30 & $\begin{array}{c}\text { Members of the local community attending a Basic } \\
\text { Computer Literacy course } \\
\text { Pretoria University - } \\
\text { Mamelodi Campus } \\
\text { Total }\end{array}$ \\
\hline
\end{tabular}

while $45 \%$ were male. We see that in terms of representativeness, there is some symmetry in gender representation (Figure 3).

Figure 4 captures of the different age ranges of the respondents, with $6 \%$ below 20 years; $39 \%$ between 20 and 25 years; $18 \%$ between 26 and 30 years; $18 \%$ between 31 and 35 years; while $18 \%$ were above 36 years. From the proportions captured by the pie chart, it is noticeable that a majority $(63 \%)$ are below the age of 30 years, which aptly places the respondents within the generation Y category typically referred to as the "millenials." The demographic section of the questionnaire also captured the educational qualifications of the respondents (Table 2).

Table 2 gives that $70 \%$ of the respondents at most had a high school certificate; and the sample frame revealed that all the members of this cohort did not have any formalized computer literacy training and lived in economically disadvantaged communities. The respondents were also not in any form of formal employment, were classified as poor, with some of the elderly members receiving social grants of some sort. Thus, our theoretical sample realized a respondent profile that can be considered as socially excluded (socially, economically and digitally).

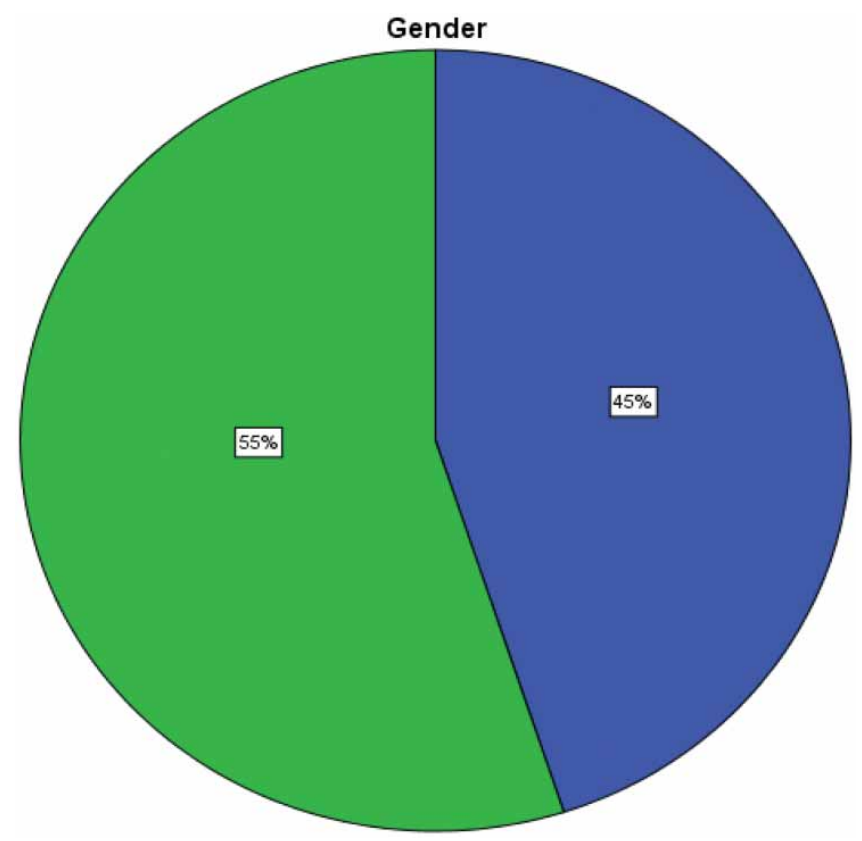

Figure 3. Gender of respondents. 


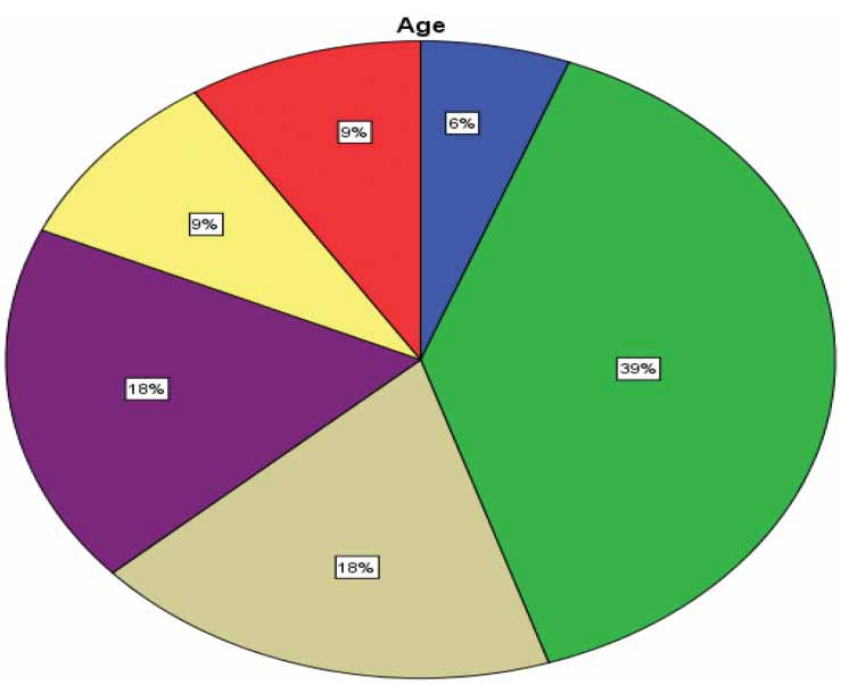

Figure 4. Age of respondents.

Table 2. Educational profile.

\begin{tabular}{lccc}
\hline Education & Frequency & Percent & Cumulative percent \\
\hline No formal qualification & 9 & 7.5 & 7.5 \\
High school graduate & 75 & 62.5 & 70.0 \\
Diploma & 8 & 6.7 & 76.7 \\
Undergraduate degree & 24 & 20.0 & 96.7 \\
Postgraduate degree & 4 & 3.3 & 100.0 \\
Total & 120 & 100.0 & \\
\hline
\end{tabular}

\subsection{Reliability analysis}

The 37 variables used to represent the e-government utility through mobile phones and Internet were assessed for reliability by computing the Cronbach's alphas. In an initial reliability analysis, Cronbach's alpha for the 37 variables was .689 (Table 3). An inspection of the item-total statistics showed that if seven (AT2, S1, S2, S4, S5, AT8 and AT14) items were removed, the overall Cronbach alpha would be improved (.739). These variables were therefore deleted, and a further check on the resulting item-total correlations showed that there is need to delete a further six items (AT3, AT4, AT12, AT13, AT15 and AT17). Further reliability analysis and deletions of variables (AT5, AC4, S10, AT19, AT20, AT11, AC5 and AT1) resulted in an improved Cronbach's alpha of .808 (Table 4), with 16 items being retained for subsequent analysis (Table 5).

\subsection{Cluster analysis}

An important goal of the study was to test the assumption that socio-demographically related respondents yield similar profiles in terms of access (A), skills (S) and attitudes (A) which would allow us to draw a consistent ASA profile of the respondents (Table 6). The 16 statements that remained after reliability analysis was conducted were coded in the following manner. Positive answers were attributed a plus (+) and negative answers a minus $(-)$ as given in Table 6. For example, a respondent who fully agreed with the statement "If I were to use my mobile 
Table 3. Reliability statistics.

\begin{tabular}{lcc}
\hline Cronbach's alpha & Cronbach's alpha based on standardized items & No. of items \\
\hline .689 & .675 & 37 \\
\hline
\end{tabular}

Table 4. Final reliability statistics.

\begin{tabular}{lcc}
\hline Cronbach's alpha & Cronbach's alpha based on standardized items & No. of items \\
\hline .808 & .809 & 16 \\
\hline
\end{tabular}

Table 5. Item-total statistics.

\begin{tabular}{lccccc}
\hline & $\begin{array}{c}\text { Scale } \\
\text { mean if } \\
\text { item } \\
\text { deleted }\end{array}$ & $\begin{array}{c}\text { Scale } \\
\text { variance if } \\
\text { item deleted }\end{array}$ & $\begin{array}{c}\text { Corrected } \\
\text { item-total } \\
\text { correlation }\end{array}$ & $\begin{array}{c}\text { Squared } \\
\text { multiple } \\
\text { correlation }\end{array}$ & $\begin{array}{c}\text { Cronbach's } \\
\text { alpha if item } \\
\text { deleted }\end{array}$ \\
\hline MarketStrategyAC1 & 42.45 & 89.039 & .324 & .319 & .803 \\
CostAC2 & 42.88 & 88.406 & .369 & .344 & .800 \\
TangiblesAC3 & 42.67 & 91.451 & .240 & .136 & .808 \\
ComplexityS3 & 42.98 & 86.747 & .446 & .356 & .795 \\
RelativeAdvantageAT6 & 43.02 & 86.084 & .488 & .375 & .792 \\
ReliabilityAT7 & 42.94 & 88.291 & .324 & .273 & .804 \\
PerceivedRiskS6 & 43.18 & 82.722 & .604 & .485 & .784 \\
MarketStrategyS7 & 42.47 & 86.285 & .418 & .353 & .797 \\
CompatibilityAT9 & 42.98 & 86.781 & .371 & .253 & .801 \\
TrialabilityAC8 & 42.69 & 84.719 & .545 & .408 & .788 \\
ComplexityS9 & 43.22 & 85.717 & .479 & .321 & .793 \\
PerceivedSocialRiskAT16 & 43.07 & 89.189 & .316 & .257 & .804 \\
TrialabilityS11 & 42.39 & 86.526 & .477 & .399 & .793 \\
PerceivedFinancialRiskAC6 & 42.97 & 87.831 & .366 & .315 & .801 \\
SocialInfluenceAT18 & 43.18 & 90.773 & .259 & .206 & .807 \\
SocialInfluenceAT10 & 43.18 & 85.036 & .528 & .451 & .790 \\
\hline
\end{tabular}

phone to access government services, it must be with a government department I am familiar with" is considered to provide an indication of a negative attitude and was awarded an Ac(Table 6). The assignment of positive and negative polarities allowed the ability to distinguish the respondents' answers in terms of bipolarities Ac+, Ac- $\mathrm{S}+, \mathrm{S}-, \mathrm{At}+$ and $\mathrm{At}-$ as given in Table 7.

The scores for the 16 statements allow for the profiling of the respondents in terms of their ASA characterization using hierarchical cluster analysis (SPSS). Various cluster outputs (5, 4, 3 and 2) were analyzed and a three cluster solution was interpretable and made theoretical sense to enable ASA characterization. The cluster analysis outputs that were considered relevant for further analysis were: agglomeration schedule (Table 8), cluster membership (Table 9) and the dendrogram (Figure 5). The dendrogram (Figure 5) provides a visual display of the clustering of the variables into three major clusters, which is confirmed by the agglomeration schedule (Table 6).

The coefficients column in the agglomeration schedule shows the distance statistic used to form clusters. According to the agglomeration schedule, the important values to consider are 
Table 6. Bipolarities.

\begin{tabular}{lccc}
\hline & 1 (strongly disagree) & Cluster means & 5 (strongly agree) \\
\hline MarketStrategyAC1 & $\mathrm{Ac}+$ & 3.30 & $\mathrm{Ac}-$ \\
CostAC2 & $\mathrm{Ac}+$ & 2.87 & $\mathrm{Ac}-$ \\
TangiblesAC3 & $\mathrm{Ac}+$ & 3.08 & $\mathrm{Ac}-$ \\
ComplexityS3 & $\mathrm{S}-$ & 2.78 & $\mathrm{~S}+$ \\
RelativeAdvantageAT6 & $\mathrm{At}-$ & 2.73 & $\mathrm{At}+$ \\
ReliabilityAT7 & $\mathrm{At}-$ & 2.81 & $\mathrm{At}+$ \\
PerceivedRiskS6 & $\mathrm{S}+$ & 2.57 & $\mathrm{~S}-$ \\
MarketStrategyS7 & $\mathrm{S}+$ & 3.28 & $\mathrm{~S}-$ \\
CompatibilityAT9 & $\mathrm{At}+$ & 2.78 & $\mathrm{At}-$ \\
TrialabilityS8 & $\mathrm{S}+$ & 3.08 & $\mathrm{~S}-$ \\
ComplexityS9 & $\mathrm{S}+$ & 2.53 & $\mathrm{~S}-$ \\
PerceivedSocialRiskAT16 & $\mathrm{At}+$ & 2.68 & $\mathrm{At}-$ \\
TrialabilityS11 & $\mathrm{S}+$ & 3.36 & $\mathrm{~S}-$ \\
PerceivedFinancialRiskAC6 & $\mathrm{Ac}+$ & 2.78 & $\mathrm{Ac}-$ \\
SocialInfluenceAT18 & $\mathrm{At}-$ & 3.40 & $\mathrm{At}+$ \\
SocialInfluenceAT10 & $\mathrm{At}+$ & 2.58 & $\mathrm{At}-$ \\
\hline
\end{tabular}

Table 7. ASA bipolarities.

\begin{tabular}{|c|c|c|}
\hline Dimension & Polarity & Description \\
\hline Ac(cess) & + & $\begin{array}{l}\text { Respondents have no problem with access to e-government using their mobile } \\
\text { phone }\end{array}$ \\
\hline Ac(cess) & - & Respondents have a problem accessing e-government from their mobile phones \\
\hline S(kills) & + & Respondents are skilled sufficiently to use mobile phones for e-government \\
\hline S(kills) & - & Respondents lack skills to use mobile phones for e-government \\
\hline At(titudes) & + & Respondents have a positive attitude toward mobile technology for e-government \\
\hline At(titudes) & - & Respondents have a negative attitude toward mobile technology for e-government \\
\hline
\end{tabular}

Table 8. Agglomeration schedule.

\begin{tabular}{|c|c|c|c|c|c|c|}
\hline \multirow[b]{2}{*}{ Stage } & \multicolumn{2}{|c|}{ Cluster combined } & \multirow[b]{2}{*}{ Coefficients } & \multicolumn{2}{|c|}{ Stage cluster first appears } & \multirow[b]{2}{*}{ Next stage } \\
\hline & Cluster 1 & Cluster 2 & & Cluster 1 & Cluster 2 & \\
\hline 1 & 7 & 11 & 93.500 & 0 & 0 & 4 \\
\hline 2 & 2 & 4 & 190.000 & 0 & 0 & 7 \\
\hline 3 & 1 & 10 & 294.500 & 0 & 0 & 10 \\
\hline 4 & 5 & 7 & 405.000 & 0 & 1 & 15 \\
\hline 5 & 16 & 19 & 521.500 & 0 & 0 & 11 \\
\hline 6 & 12 & 13 & 641.500 & 0 & 0 & 11 \\
\hline 7 & 2 & 15 & 763.667 & 2 & 0 & 14 \\
\hline 8 & 8 & 14 & 886.167 & 0 & 0 & 12 \\
\hline 9 & 6 & 9 & 1024.167 & 0 & 0 & 14 \\
\hline 10 & 1 & 3 & 1167.667 & 3 & 0 & 12 \\
\hline 11 & 12 & 16 & 1327.917 & 6 & 5 & 13 \\
\hline 12 & 1 & 8 & 1492.217 & 10 & 8 & 15 \\
\hline 13 & 12 & 17 & 1671.867 & 11 & 0 & 18 \\
\hline 14 & 2 & 6 & 1866.400 & 7 & 9 & 17 \\
\hline 15 & 1 & 5 & 2062.225 & 12 & 4 & 16 \\
\hline 16 & 1 & 18 & 2313.156 & 15 & 0 & 17 \\
\hline 17 & 1 & 2 & 2579.829 & 16 & 14 & 18 \\
\hline 18 & 1 & 12 & 2954.947 & 17 & 13 & 0 \\
\hline
\end{tabular}


Table 9. Cluster membership.

\begin{tabular}{lcc}
\hline Case & 3 clusters & Assigned polarity \\
\hline MarketStrategy(AC1) & 1 & Act \\
TangiblesAC3 & 1 & Act \\
RelativeAdvantageAT6 & 1 & At - \\
PerceivedRiskS6 & 1 & $\mathrm{~S}-$ \\
TrialabilityS8 & 1 & $\mathrm{~S}+$ \\
SocialInfluenceAT10 & 1 & $\mathrm{At}-$ \\
MarketStrategyAC7 & 1 & $\mathrm{AC}+$ \\
TrialabilityS11 & 1 & $\mathrm{~S}+$ \\
Age & 1 & $\mathrm{Ac}+$ \\
CostAC2 & 2 & $\mathrm{~S}-$ \\
ComplexityS3 & 2 & $\mathrm{At}-$ \\
ReliabilityAT7 & 2 & $\mathrm{At}+$ \\
CompatibilityAT9 & 2 & $\mathrm{Ac}+$ \\
PerceivedFinancialRiskAC6 & 2 & $\mathrm{~S}+$ \\
ComplexityS9 & 3 & $\mathrm{At}+$ \\
PerceivedSocialRiskAT16 & 3 & $\mathrm{At}+$ \\
SocialInfluenceAT18 & 3 & \\
Gender & 3 & \\
Education & 3 & \\
\hline
\end{tabular}

the coefficients, which provide an indication as to the number of clusters which can meaningfully be extracted. Starting with the bottom coefficient (stage 18), the analysis progresses upwards while on the lookout for the point at which there is the greatest jump between any two adjacent coefficients. The greatest jump occurs between coefficients 2313.156 (stage 16) and 2062.225 (stage 15), which indicates that three meaningful clusters are likely (counting from the bottom). The agglomeration schedule also shows how the various items have been clustered through the various stages. For instance, at stage 1, items 7 (S6) and 11 (At10) are combined in a cluster as shown in the dendrogram (Figure 1) and confirmed in the Table 9 of cluster membership. According to Table 8, the two items belong to cluster 1. Likewise, at stage 2 in the agglomeration schedule, items 2 (Ac2) and 4 (S3) are combined into cluster 2. The combination of the various items as confirmed through the dendrogram and the agglomeration schedule results in the overall cluster membership given in Table 8 and summarized in Table 9.

Cluster 1 comprised of the following items, taking into account the polarities captured in Table 7:

- MarketStrategy(AC1): If I were to use my mobile phone to get government services, it must be with a government department I am familiar with

- TangiblesAC3: The way to access government services using a mobile phone is not clear

- RelativeAdvantageAT6: I do not know how to use mobile phones to access government services

- PerceivedRiskS6: I cannot use the mobile phone to access government services by myself

- TrialabilityS8: I would like to see others use mobile phones to access government services before I try it out for myself

- SocialInfluenceAT10: I am interested in using the mobile phone to get government services, but only if my friends and family are doing so

- MarketStrategyS7: If I would consider accessing government services using my mobile phone, someone need to explain me how to do it 
PerceivedRiskS6

SociallnfluenceAT10

RelativeAdvantageAT6

MarketStrategyS7

TrialabilityS11

MarketStrategyAC1

TrialabilityAC8

TangiblesAC3

Age

$>\operatorname{CostAC2}$

ComplexityS3

PerceivedFinancialRiskAC6

ReliabilityAT7

CompatibilityAT9

SociallnfluenceAT18

Education

Complexitys9

PerceivedSocialRiskAT16

Gender

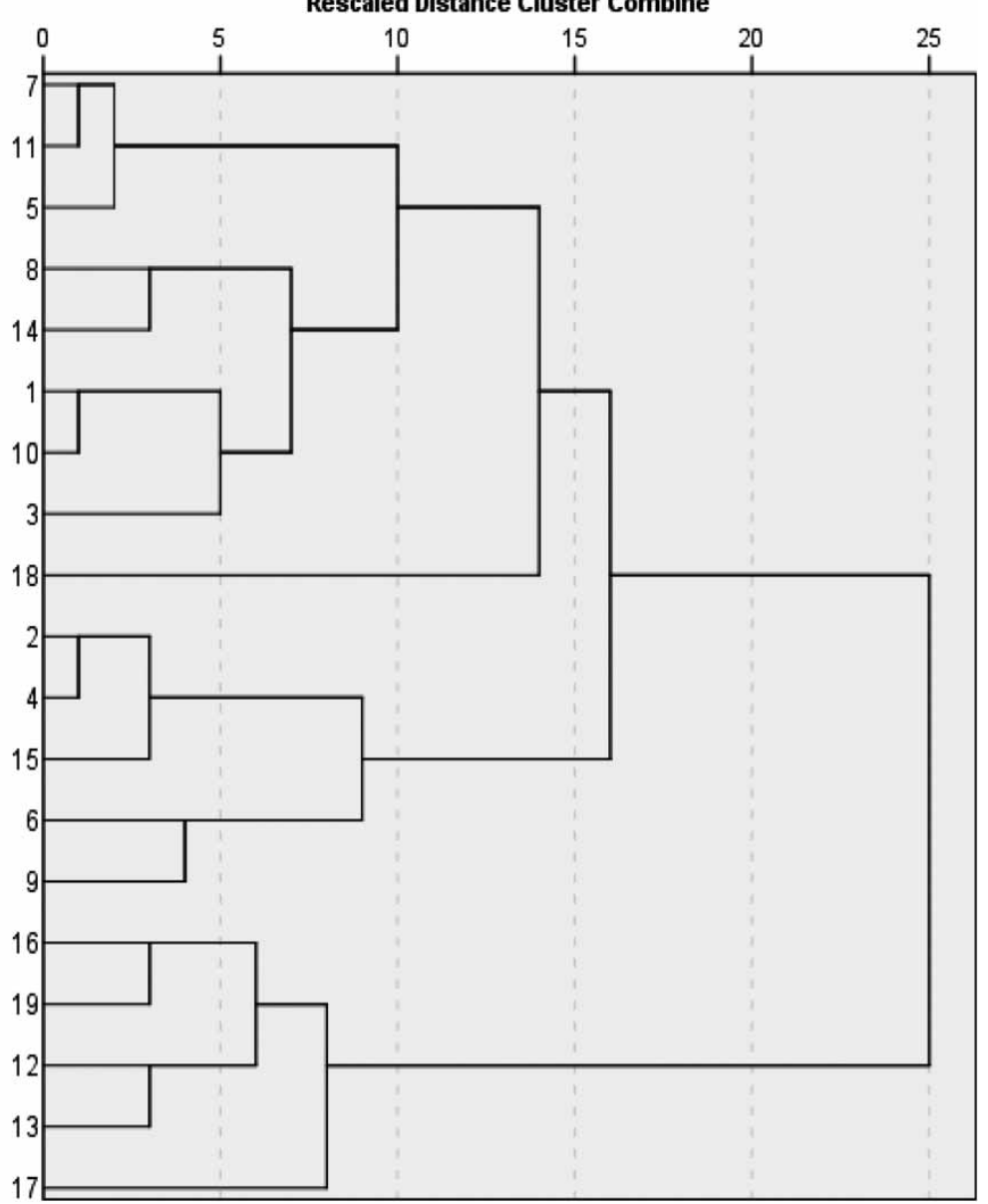

Figure 5. Dendrogram.

- TrialabilityS11: Before using the mobile phone for accessing government services, I would like the advice of some people

According to the polarities derived from the means, respondents considered that accessing government services using mobile phones can be with any government department (AC1); that the process is clear (AC3); and that they can try out the process independently of others (S6, S7, S8, S11; At10). There were no negative polarities associated with Cluster 1, with a majority of the respondents indicating that they possess the skills (S6, S7, S8 and S11) and the interest (At10) to use the phone independently of any social influence to access (AC1 and AC3) government services. We can therefore name this cluster, "Capable and Interested within a Social Network." Cluster 1 was also combined with the age variable, and the descriptive analysis performed earlier showed that $63 \%$ of the respondents were below the age of 30 , which may allow us to make a preliminary claim that the "youth" have the skills and the interest to use mobile phones for e-government access, but the influence of their social network cannot be ignored in embedding e-government as part of the mobile phone artifact. This claim is backed by several studies that show how the mobile phone is becoming a communications 
platform for the youth around the world. Thus, the fact that "age" clusters with these items confirms assertions that have been made in other studies. Given this finding, a number of implications can be envisaged, especially related to how e-government can be crafted and positioned taking into account the mobile platform.

Cluster 2 comprised of the following items, taking into account the polarities captured in Table 7:

- CostAC2: Using the mobile phone to access government services seems expensive

- ComplexityS3: I fear that using a mobile phone for government services is rather complicated for me

- ReliabilityAT7 : I doubt that the mobile phone is good enough for providing government services

- CompatibilityAT9: I prefer walking into a government office for service instead of using the Internet

- PerceivedFinancialRiskAC6: I fear that using my mobile phone to communicate with government would exceed my budget

An analysis of Cluster 2 reveals that three items had positive polarities (AC2, AT9 and AC6); while two items had negative polarities (S2 and AT7). Item AC2 sought to assess the perception of respondents regarding the issue of cost of telecommunications oft mentioned as a hindrance in developing countries. The overriding sentiment rebuffs such an assertion and respondents largely regard using mobile phones for e-government services as inexpensive. It may be that the need for government services online far outweighs the perceived notion of high telecommunications costs. AT9, the third item with positive polarity also negates the perception that citizens prefer walking to a government office for services if there is access through the Internet. This perception should provide impetus for considering the Internet and specifically, mobile technology as an e-government platform. The third positive polarity also focused on aspects of access costs, and a majority of the respondents are of the opinion that using the mobile phone for e-government will not exacerbate their expenses. On the other hand, the negative polarities were captured by AT7, which reinforces the view that in fact using the mobile phone for e-government is not good enough or is inadequate. The other item with negative polarity (S3) was skills-related, in which respondents expressed fear that using the mobile phone for e-government services may be complicated. So the negative polarities are related to attitude and skills, which broods some form of skepticism toward the use of mobile phones for e-government; though there are dominant positive polarities in items AC2, AT9 and AC6. We can therefore refer to the group of respondents that formed this cluster as "Skeptical Optimists" given that they prefer online services over manual (AT9) and that access costs/budget are within their reach; though there may be complications in using the mobile phone for government services.

Cluster 3 had three items related to the utility of mobile technology for e-government access (S9, AT16 and AT18) but was also demographically clustered with gender and education. All the three items had positive polarities and emphasized the following:

- ComplexityS9: I fear that using the mobile phone to access government services will make it more complicated to use.

- PerceivedSocialRiskAT16: If I were to use the mobile phone to get in touch with government, my friends and family would look odd at me.

- SocialInfluenceAT18: Even if I am interested, I would not access government services through my mobile phone if my friends and family have a negative opinion about it.

All the three items had positive polarities, thus the respondents disagreed that using the mobile phone for e-government access will make it (mobile phone) complicated to use (S9); 
which is linked to skills related to using mobile phone. So the addition of a service in the device does not make it more complicated to use. The other two items were related to attitudes, where respondents negated the view that the perception and opinion of family and friends does not influence the decision to use mobile phone for e-government (AT16 and AT18). We can therefore refer to this cluster as "Mobile Government Optimists." The items in this cluster are also cluster with the gender and education variables. As was shown in the descriptive section of the analysis, there were $55 \%$ female and $45 \%$ male respondents; which captured a proportionate representation of the gender variable. However, it is in linking the level of education of the respondents that we think the results of this cluster are instructive. As per the descriptive analysis, $70 \%$ of the respondents only had a formal education of up to 12 years and did not qualify to enroll at university. They are therefore regarded as "uneducated," low skilled and as was shown in our sample, they are poor. Yet despite their level of education, the positive polarities captured in this cluster point to strong attitudes supportive of using the mobile computing platform as a basis for e-government.

\section{Discussion of results}

The emphasis in the literature review was to position the notion of m-government within developing countries within the ICT4D discourse. Part of the argument was that for e-participation to be realized a focus on the mobile computing platform is inevitable in Africa and that ICT4D metaphor provide an adequate structuring device in a developing country's context. In this section, we structure the discussion of results around the concept of "Bricolage," to understand the analysis above, and using a phased approach, link the results to implications for the realization of e-participation strategy in the developing nations of Africa.

\section{1 “Bricolage" as the metaphor for sustainable e-participation in Africa}

From the analysis reported earlier, we make the claim that; while the mobile technology platform was not intended for realizing e-government, it offers a potential for realizing the sustainability of the e-government concept in Africa. In other words, mobile technology, need to be embraced as a necessary resource for realizing the goals of e-government, as revealed from the analyses above. For instance, our analysis showed that a majority of respondents were clustered as "Mobile Government Optimists," yet pointedly, the demographic profile of the respondents are socially excluded and belong to the "bottom of the pyramid" (economically and socially). The optimism, expressed by this demographic profile, allows us to make the claim that for social sustainability of e-government and its various forms to be realized, the readily available resource of mobile devices needs to be taken into account when conceptualizing an e-participation strategy. Thus, the realization of the public value of e-government in the developing nations implies taking the opportunity for building e-government solutions on a mobile platform, and in the language of Bricolage, is a resource that allows for "making do by applying combinations of the resources at hand to new problems and opportunities" (Baker \& Nelson, 2005, p. 333). The import of this finding is to debunk the "myth" of technological complexity of the mobile phone as a platform for e-government cognizant of studies that show that the issue of concern in "digital divide" is on electronic illiteracy (Ochara, 2012). The positive attitude and the skills apparent in mobile phone use amongst this group requires moving beyond the constraint of this "myth" and assumption to boldly adopt and adapt the mobile computing platform as one of the bases for e-participation. However, given this opportunity provided by mobile technology for crafting an e-participation strategy, what challenges abound? The next two sections attempt a resolution based on the outcomes of the prior analysis. 


\subsection{Network Bricolage for sustainable mass scale adoption}

The cluster analysis that was referred to as "Capable and Interested within a Social Network" provides some indication of how to achieve mass scale by focusing on socially excluded groups. The demographic profile of the respondents has been shown to belong to the socially disadvantaged in the community and as was analyzed in Table 7, and the problem of mass scale adoption is rarely of access (as was shown by the positive polarities of AC1, AC3 and AC7 in conjunction with S8 and S11) but is typically related to factors that hinge around attitudes (AT7 and AT10) and skills (S6). This confirms sentiments that have been expressed by ICT4D authors who recommend looking beyond the oft mentioned problem of equitable access for redressing the digital exclusion problem (Gomez \& Gould, 2010; Roman, 2003). In addressing mass scale adoption of e-government, the clustering of variables (AT7, AT10 and S6) provide, in a preliminary sense, a linkage to making use of the social networks of individuals as a basis for improving the social resource base (see Warschauer, 2004) for individuals interested in e-government. It is in elevating the social network of the individual that the metaphor of network Bricolage becomes appropriate as a lens for explaining mass scale adoption.

The social network of the individuals is instrumental in building confidence in attitudes and ability to use mobile devices for e-government services. This is linked to the improvement of the social capital or social resources of a community, hence an individual. There are two aspects related to developing confidence, which is at the individual level as well as at the broader social network (various organizing forms) level. Organizing forms are the immediate structures that the individual interacts with frequently to help in ordering his/her life. These organizing forms are normally not part of the mainstream public sector and include institutions such as churches, schools, market places, informed retailers, community centers, family and friends. This form of social coordination is based on a network mode of governance (Lowndes \& Skelcher, 1998), and thus network Bricolage inevitably becomes the process for developing the social capital for socially excluded groups. If the social resource base is weak, then the result is weak communities and individuals who are not empowered, with negative attitudes and skills necessary for empowering them to use mobile devices for e-government. A strong social resources base results in confident communities.

In sum, the implication of the finding, that individual fitting the demographic profile of this study are actually "capable and interested in using mobile devices for e-government, within their social network" brings to the fore the role that social capital plays in mass scale adoption of e-services. Developing of social capital is typically achieved within informal networks and organizing forms, sometimes outside the control of e-government planners and implementers. Thus while recognizing the influence of the social network in influencing mass scale adoption of various forms of e-services, at the practical level, how to mainstream local practices in e-government strategy still remains a challenge.

\subsection{Electronic literacy as a basis for e-participation strategy}

Insights from the analysis of Cluster 2 (Table 7), which was named as "Skeptical Optimists," point toward a need to crafting the e-participation strategy hinged on the concept of electronic literacy. Electronic literacy encompasses computer literacy, information literacy, multimedia literacy and computer-mediated literacy (see Warschauer, 2004). The positive clustering of the variables and respondents around AC2, AT9 and AC6 provides unequivocal preference of online government services (where applicable) over manual services, thus the connotation of optimists in the naming of the cluster. However, the optimism is tempered by negative polarities related to S3 (using a mobile phone for government services will be complicated) and AT7 (mobile phone is not good enough for government services), thus the connotation of skepticism 
in the naming of the cluster. We link the skepticism portrayed by the analysis as a quest to be convinced (resulting in change of attitude - AT7) as well as uncertainty regarding the level of skills required for using a mobile phone for e-government (S3). These two challenges that broods skepticism on the utility of mobile technology for e-government is partly addressed by re-orienting the e-government and e-participation strategy as founded on an electronic literate population. Attention on fostering e-literacy emphasizes the use rather than connectivity, which has hitherto been the vocable for galvanizing national information infrastructure investments in Africa; yet e-literacy continue to be ignored. Therefore, priority should concentrate on information and computer literacy, which can be achieved through the mediation of the various forms of organizing closer to the individual actors.

\section{Conclusions}

The paper focuses the social sustainability of e-government projects by considering the role that mobile technology can play amongst socially excluded groups in Africa. The results indicate that, despite the predominant perception that socially excluded groups typically lack the skills, equitable access and the right attitudes for e-inclusion (Verdegem \& Verhoest, 2009); mobile technology provides a viable platform for enhancing e-participation. The exploration showed that the socially excluded clusters of individuals are positive about the possibilities of mobile technology even though there are minimal formal structures and policy guidelines on how mobile technology can play a role in e-participation. That "tinkering" and Bricolage is critical in shaping the skills and attitudes related to the use of mobile phones for e-government access, despite their social exclusion from the mainstream of society. Further that daunting decisions related to how mobile technology can be used for e-government are best handled within local organizing forms, which enabled us to access these local connections using the metaphor of network Bricolage. In other words, the social capital necessary for enhancing e-participation of individuals are best maximized through the local organizing forms.

The recommendation that emanates from this claim is that in order to improve e-participation of socially excluded groups, local organizing forms and the formal institutional infrastructure of the government need to be "joined up." This requires linking disparate organizing and the administrative institutions of governance. The results also highlighted skepticism related to the potential of mobile technology in augmenting government services. However, our analysis revealed that the skepticism is partly linked to aspects of electronic illiteracy. Thus the recommendation is that for egovernment to move beyond myth status, ICT education should embrace electronic literacy, not only in formal educational setups but also in work practices. It is hoped that future research can focus on validating these findings with the overall vision geared toward anchoring e-government initiatives on a mobile computing model that continues to play a significant role in developing national information infrastructures of nations in Africa.

However, we see the study's contribution as exploratory and require extension due to a number of limitations. The first limitation is linked to the sample size of 120 , which limits the generalizability of findings; even though the study forms a foundation for other studies that can validate these findings. This study was also limited to socially excluded groups in the urban areas. There is a need to conduct similar study across several clusters (rural and urban) across different countries to allow for more generalizability of findings. The second limitation was the focus on the social sustainability factors in exclusion to other factors related to economic sustainability. This was deliberate to enable us delve deeper into specific aspects related to social sustainability. However, this creates a need to explore linkages between factors that address social sustainability of using the mobile platform with other economic-related factors. A qualitative research strategy may provide further depth into the research topic to identify different 
perceptions. Despite the limitations highlighted, this research is still critical since it has covered a relatively nascent area, especially when the context of developing countries is taken into account. While taking into account that no finite generalizations can be drawn as well, the results still provide a snapshot of how social sustainability of e-government can begin to be realized through the mobile technology platform.

\section{Notes on contributors}

Dr. Nixon Muganda Ochara is a Senior Lecturer and Researcher at the University of Pretoria, Department of Informatics. He obtained his PhD in Information Systems in 2009 from the Department of Information Systems, University of Cape Town, South Africa. The focus of his PhD thesis was anchored on a nomadic framework for conceptualizing e-government for developing countries. In the last eight years, he has actively engaged in research focusing on e-government in developing countries, with a particular focus on how to address issues related to social exclusion. His research has been published in international conferences and journals. Prior to joining academia, he worked in the IT services industry in various capacities.

Ms. Tendani Mawela is a Lecturer and PhD candidate at the University of Pretoria, Department of Informatics. Her PhD focuses on the conceptualization of Transformational Government with regards to the value and impact of e-Government programmes within African countries. Ms. Mawela's research interests include e-Government, e-Participation, ICT for Development, ICT Governance and IT Project Management.

\section{References}

Abrahams, L., \& Newton-Reid, L. (2008). E-governance for social and local economic development: Gauteng city region perspective. Johannesburg: LINK Center, University of Witwatersrand.

African Union. (2010). ICT for development. In 14th African union summit on "information and communication technologies in Africa: Challenges and prospects for development". Addis Ababa: Author. Retrieved from http://www.africa-union.org/root/au/conferences/2010/january/summit/14thsummit. html

Ali, M., \& Bailur, S. (2007). The challenge of "sustainability" in ICT4D - is Bricolage the answer. In 9th International conference on social implications of computers in developing countries. Sao Paulo, Brazil. Retrieved from http://www.ifipwg94.org.br/fullpapers/R0010-2.pdf

Almuwil, A., Weerakkody, V., \& El-Haddadeh, R. (2011). A conceptual study of factors influencing e-inclusion. In European, Mediterranean and Middle Eastern conference on information systems (pp. 30-31). May 30-31 2011, Athens, Greece.

Andrade, A., \& Joia, L. A. (2011). Organizational structure and ICT strategies in Brazilian judiciary system. Government Information Quarterly, 29(1), S32-S42.

Avgerou, C. (2010). Discourses on ICT and development. Information Technologies and International Development, 6(3), 1-18.

Avgerous, C. (2008). Information systems in developing countries: A critical research review. Journal of Information Technology, 23(3), 133-146.

Bailey, A. (2009). Issues affecting the social sustainability of telecentres in developing contexts: A field study of sixteen telecentres in Jamaica. Electronic Journal of Information Systems in Developing Countries, 36(4), 1-18.

Bailur, S. (2007). Using stakeholder theory to analyze telecenter projects. Information Technologies and International Development, 3(3), 61-80.

Baker, T., \& Nelson, R. E. (2005). Creating something from nothing: Resource construction through entrepreneurial Bricolage. Administrative Science Quarterly, 50(3), 329-366.

Basu, S. (2004). E-government and developing countries: An overview. International Review of Law, Computers and Technology, 18, 109-132.

Belanger, F., \& Carter, L. (2009). The impact of the digital divide on E-government use. Communications of the ACM, 52(4), 132-135.

Benington, J., \& Moore, M. H. (2011). Public value in complex and changing times. In J. Benington and M. H. Moore (Eds.), Public value: Theory and Practice (pp.1-30). Basingstoke: Palgrave Macmillan.

Bhuiyan, S. H. (2011). Modernizing Bangladesh public administration through e-governance: Benefits and challenges. Government Information Quarterly, 28(1), 54-65. 
Bilbao-Osorio, B., Dutta, S., \& Lanvin, B. (2013). Global information technology report 2013: Growth and jobs in a hyperconnected world. Geneva: World Economic Forum and INSEAD. Retrieved July 28, 2013.

Chou, T. C., Chen, J. R., \& Pu, C. K. (2008). Exploring the collective actions of public servants in E-government development. Decision Support Systems, 45, 251-265.

Ciborra, C. (1998). Crisis and foundations: An inquiry into the nature and limits of models and methods in the information systems discipline. Journal of Strategic Information Systems, 7, 5-16.

Collier, P. (2008). The bottom billion: Why the poorest countries are failing and what can be done about it. New York: Oxford University Press.

Department of Communications. (2012). Strategic plan 2012-2017. Pretoria: Government Printers, Republic of South Africa.

Donat, E., Brandtweiner, R., \& Kerschbaum, J. (2009). Attitudes and the digital divide: Attitude measurement as instrument to predict internet usage. Informing Science: The International Journal of an Emerging Transdiscipline, 12(1), 37-56.

Edmunds, R., Thorpe, M., \& Conole, G. (2012). Student attitudes towards and use of ICT in course study, work and social activity: A technology acceptance model approach. British Journal of Educational Technology, 43(1), 71-84.

Garud, R., \& Karnøe, P. (2003). Bricolage versus breakthrough: Distributed and embedded agency in technology entrepreneurship. Research Policy, 32(2), 277-300.

Goldsmith, A. (2007). Is governance reform a catalyst for development? Governance, 20(2), 165-186.

Gomez, R., Abokhodair, N., Bayo, I., \& Park, M. (2013). Computer training to empower day laborers: A heat map to address emotional barriers and technical skills. In 46th Hawaii international conference on system sciences.

Gomez, R., \& Gould, E. (2010). The "cool factor" of public access to ICT users' perceptions of trust in libraries, telecenters and cybercafe's in developing countries. Information Technology \& People, 23(3), 247-264.

Grindle, M. (2007). Good enough governance revisited. Development Policy Review, 25(5), 533-574.

Grindle, M. (2011). Good enough governance revisited. Development Policy Review, 29(1), 199-221.

Hanna, N. (2008). Transforming government and empowering communities: Sri Lankan experience with E-development. Washington, DC: The World Bank.

Hayes, N., \& Westrup, C. (2012). Context and the processes of ICT for development. Information and Organization, 22(1), 23-36.

Heeks, R. (2002). E-government in Africa: Promise and practice. Information Polity, 7(2), 97-114.

Heeks, R. (2008). ICT 2.0: The next phase of applying ICT for international development. Computer, 41, $26-33$.

Heeks, R. (2010). Do information and communication technologies (ICTs) contribute to development? Journal of International Development, 22(5), 625-640.

Heikkinen, M. V., Nurminen, J. K., Smura, T., \& Hammainen, H. (2012). Energy efficiency of mobile handsets: Measuring user attitudes and behavior. Telematics and Informatics, 29(4), 387-399.

Hilbert, M. (2010). When is cheap, cheap enough to bridge the digital divide? Modeling income related structural challenges of technology diffusion in Latin America. World Development, 38(5), 756-770.

Ho, A. (2002). Reinventing local government and the E-government initiative. Public Administration Review, 62, 434-444.

Hüsing, T., \& Selhofer, H. (2002, January). The digital divide index - a measure of social inequalities in the adoption of ICT. ECIS, 1273-1286.

ITU. (2013). ICT facts and figures. Retrieved July 28, 2013, from The World in 2013: http://www.itu.int/en/ ITU-D/Statistics/Documents/facts/ICTFactsfigures2013.pdf

IWS. (2013). Internet usage statistics for Africa. Retrieved from Internet World Stats: http://www. internetworldstats.com/stats1.htm

Jaeger, P. T., \& Thompson, K. M. (2003). E-government around the world: Lessons, challenges, and future directions. Government Information Quarterly, 20, 389-394.

Khan, G. F., Moon, J., Rhee, C., \& Rho, J. J. (2010). E-government skills identification and development: Toward a stage-based user - centric approach for developing countries. Asia Pacific Journal of Information Systems, 20(1), 1-31.

Klecun, E. (2008). Bringing lost sheep into the fold: Questioning the discourse of the digital divide. Information Technology \& People, 21(3), 267-282.

Lai, J. Y., \& Chang, C. Y. (2011). User attitudes toward dedicated e-book readers for reading: The effects of convenience, compatibility and media richness. Online Information Review, 35(4), 558-580. 
Lowndes, V., \& Skelcher, C. (1998). The dynamics of multi-organizational partnerships: An analysis of changing modes of governance. Public Administration, 76(Summer), 313-333.

Markus, M. (2000). Toward an integrative theory of risk and control. In R. Baskerville, J. Stage, \& J. I. DeGross (Eds.), Organizational and social perspectives on information technology (pp. 167-178). Boston, MA: Kluwer Academic.

Meynhardt, T. (2009). Public value inside: What is public value creation? International Journal of Public Administration, 32(3-4), 192-219.

Misuraca, G. (2009). E-government 2015: Exploring M-government scenarios, between ICT - driven experiments and citizen-centric implications. Technology Analysis \& Strategic Management, $21(3), 407-424$.

Mukabeta, M., Owei, V., \& Alexander, H. (2008). Questioning the pace and pathway of e-government development in Africa: A case study of South Africa's Cape Gateway project. Government Information Quarterly, 25, 757-777.

Mutula, S. M., \& Van Brakel, P. (2007). ICT skills readiness for the emerging global digital economy among small businesses in developing countries: Case study of Botswana. Library Hi Tech, $25(2), 231-245$.

Ndou, V. (2004). E-government for developing countries: Opportunities and challenges. The Electronic Journal of Information Systems in Developing Countries, 18, 1-24.

Norris, P. (2001). Digital divide: Civic engagement, information poverty, and the internet worldwide. Cambridge: Cambridge University Press.

Oates, J. (2006). Researching information systems and computing. Los Angeles, CA: Sage.

Ochara, N. (2012). Grassroots community participation as a key to e-governance sustainability in Africa. African Journal of Information and Communication, 12, 26-47.

Oliver, C., \& McKague, K. (2009). Sustainable local enterprise networks: Network Bricolage as institutional entrepreneurship in low-income economies. Institutional theory conference, 20 (p. 2011). Edmonton: University of Alberta.

Reffat, R. (2003). Developing successful E-government. Working paper. School of Architecture, Design Science and Planning, University of Sydney, Sydney.

Roman, R. (2003). Diffusion of innovations as a theoretical framework for telecenters. Information Technologies and International Development, 1(2), 55-68.

Silva, L., \& Westrup, C. (2009). Development and the promise of technological change. Information Technology and Development, 15, 59-65.

Sipior, J. C., \& Ward, B. T. (2012). Bridging the digital divide for e-government inclusion: A United States case study. Case Studies in E-Government, 1, 167.

STATSSA (2012). Census 2011 - key results. Pretoria: Author.

United Nations (2012). United Nations E-government survey 2012: E-government for the people. uthor.

Van Deursen, A., \& Van Dijk, J. (2010). Measuring internet skills. International Journal of HumanComputer Interaction, 26(10), 891-916.

Van Dijk, J., \& Hacker, K. (2003). The digital divide as a complex and dynamic phenomenon. The Information Society, 19(4), 315-326.

Verdegem, P., \& Verhoest, P. (2009). Profiling the non-user: Rethinking policy initiatives stimulating ICT acceptance. Telecommunications Policy, 33, 642-652.

Warschauer, M. (2004). Technology and social exclusion: Rethinking the digital divide. Cambridge, MA: MIT Press.

Wolcott, P., Kamal, M., \& Qureshi, S. (2008). Meeting the challenges of ICT adoption by micro-enterprises. Journal of Enterprise Information Management, 21(6), 616-632.

Wunderlich, N. V., Wangenheim, F. V., \& Bitner, M. J. (2013). igh tech and high touch a framework for understanding user attitudes and behaviors related to smart interactive services. Journal of Service Research, 16(1), 3-20.

Yates, D. J., Gulati, G. J., \& Tawileh, A. (2010). Explaining the global digital divide: The impact of public policy initiatives on digital opportunity and ICT development. In System Sciences (HICSS), 2010 43rd Hawaii International Conference on (pp. 1-10). IEEE.

Yıldız, M., \& Saylam, A. (2013). E-government discourses: An inductive analysis. Government Information Quarterly, 30(2), 141-153.

Zhang, P., \& Sun, H. (2009). The complexity of different types of attitudes in initial and continued ICT use. Journal of the American Society for Information Science and Technology, 60(10), 2048-2063. 


\section{Appendix}

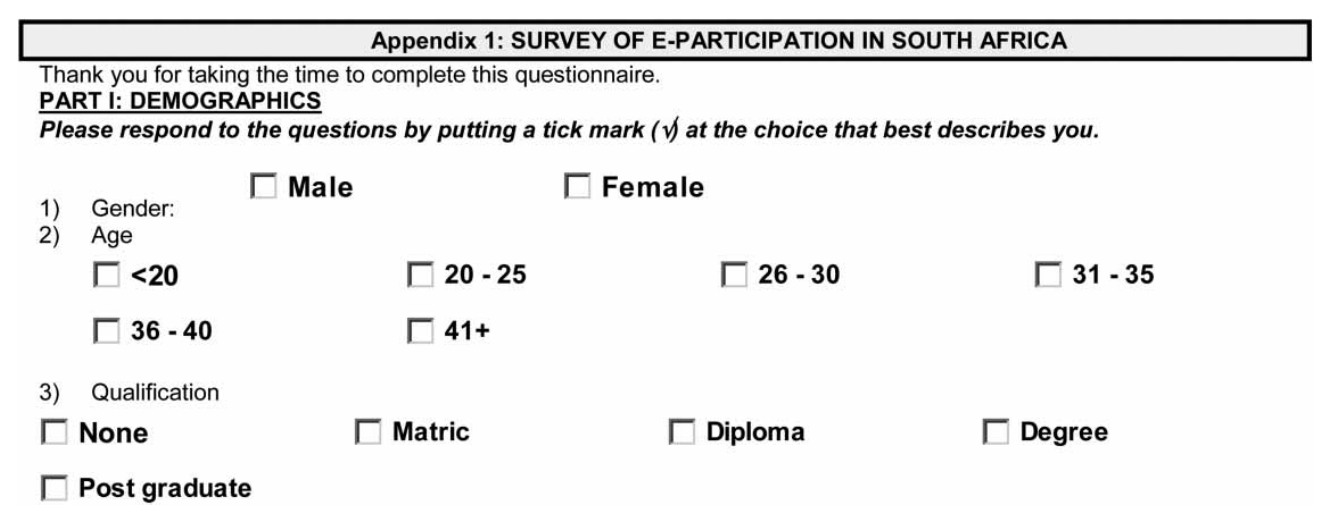

Part II: Assessing e-government utility for e-participation

Please read the following statements and indicate to what extent you agree or disagree with the statements by putting one tick mark $(\sqrt{ })$ on your choice in the grey shaded area on the right hand side below.

Aspects related to Access, Skills Attitude Toward E-Government

1. ENJOYMENT: Using the mobile phone to access government services is ridiculous

2. SOCIAL INFLUENCE: When my friends are using the mobile phone to access government services, I will consider using it myself

3. COMPLEXITY: The mobile phone is user friendly to me

At

4. MARKET STRATEGY: If I were to use my mobile phone to get government services, it must be with a government department I am familiar with

5. COST: Using the mobile phone to access government services seems expensive

6. TANGIBLES: The way to access government services using a mobile phone is not clear

7. IMAGE/PRESTIGE: Using the mobile phones to access government services improves my image and social status

8. PRODUCT KNOWLEDGE: I consider myself well informed about why mobile phones should be used for getting government services

9. COMPLEXITY: I fear that using a mobile phone for government services is rather complicated $\mathrm{S}$ for me

10. OPTIMISM: The fast technological developments are a good thing

11. SELF-EFFICACY: I have no problem using the Internet by myself to get government services

12. SOCIAL INFLUENCE: I sometimes discuss with my friends how government can provide services using the Internet

13. OBSERVABILITY: I am perfectly able to explain the strengths and weaknesses of the Internet $\mathrm{S}$ to others

14. RELATIVE ADVANTAGE: I do not know how to use mobile phones to access government At services

15. WILLINGNESS TO PAY: Using my mobile phone to get access to government is something I Ac really want

16. RELIABILITY: I doubt that the mobile phone is good enough for providing government services

17. PERCEIVED RISK: I cannot use the mobile phone to access government services by myself

18. MARKET STRATEGY: If I would consider accessing government services using my mobile phone, someone need to explain to me how to do it

19. RELATIVE ADVANTAGE: The benefits of using the mobile phone to access government services are more important than the disadvantages for me

20. COMPATIBILITY: I prefer walking into a government office for service instead of using the At Internet 
21. COST: Using the mobile phone to access government services will probably be too expensive Ac for many people

22. TRIALABILITY: I would like to see others use mobile phones to access government services before I try it out for myself

23. SOCIAL INFLUENCE: I am interested in using the mobile phone to get government services, At but only if my friends and family are doing so

24. SOCIAL INFLUENCE: If I use the mobile phone to connect to the government, it would At certainly explain something about me and my personality

25. COMPLEXITY: I fear that using mobile phone to access government will make it more $\quad S$ complicated to use

26. INNOVATIVENESS: Since I already know about the Internet, I will find out how more about e- At government services

27. OPINION LEADERSHIP: My friends and family will certainly come to me for advice concerning the using the of Internet for government information

28. RELATIVE ADVANTAGE: Using the mobile phone to get government services and to give feedback on service delivery will make it easier for me

29. OPTIMISM: If you do not want to be left behind, using the Internet is necessary

30. VOLUNTARINESS: If I was to use my mobile phone to access government services, it would completely be my own decision without influence from anybody

31. PERCEIVED SOCIAL RISK: If I were to use the mobile phone to get in touch with government At over service delivery, my friends and family would look odd at me

32. COMPATIBILITY: Using the mobile phone for Internet access fits in my lifestyle

33. TRIALABILITY: Before using the mobile phone for accessing government services, I would like the advice of some people

34. PERCEIVED FINANCIAL RISK: I fear that using my mobile phone to communicate with government would exceed my budget

35. SOCIAL INFLUENCE: Even if I am interested, I would not access government services through my mobile phone if my friends and family have a negative opinion toward it

36. SOCIAL INFLUENCE: Most of my family and friends are certainly enthusiastic about using At Internet at home

37. RELIABILITY: I think it is not safe to send sensitive information to the government using the Internet or mobile phones 